\title{
Impact of levosimendan on weaning from peripheral venoarterial extracorporeal membrane oxygenation in intensive care unit
}

\author{
Shamir Vally ${ }^{1}$, Cyril Ferdynus ${ }^{2,3}$, Romain Persichini ${ }^{1}$, Bruno Bouchet ${ }^{1}$, Eric Braunberger ${ }^{4}$, Hugo Lo Pinto ${ }^{1}$,
}

Olivier Martinet ${ }^{1}$, David Vandroux ${ }^{1}$, Thomas Aujoulat ${ }^{1}$, Jérôme Allyn ${ }^{1}$ and Nicolas Allou ${ }^{1,5^{*}}$

\begin{abstract}
Background: Few data are available on the impact of levosimendan in refractory cardiogenic shock patients undergoing peripheral venoarterial extracorporeal membrane oxygenation (VA-ECMO). The aim of this study was to evaluate the impact of levosimendan on VA-ECMO weaning in patients hospitalized in intensive care unit (ICU).

Methods: This retrospective cohort study was conducted in a French university hospital from 2010 to 2017. All patients hospitalized in ICU undergoing VA-ECMO were consecutively evaluated.

Results: A total of 150 patients undergoing VA-ECMO were eligible for the study. Thirty-eight propensity-matched patients were evaluated in the levosimendan group and 65 in the non-levosimendan group. In patients treated with levosimendan, left ventricular ejection fraction had increased from $21.5 \pm 9.1 \%$ to $30.7 \pm 13.5 \%(P<0.0001)$ and aortic velocity-time integral from $8.9 \pm 4 \mathrm{~cm}$ to $12.5 \pm 3.8 \mathrm{~cm}(P=0.002) 24 \mathrm{~h}$ after drug infusion. After propensity score matching, levosimendan was the only factor associated with a significant reduction in VA-ECMO weaning failure rates (hazard ratio $=0.16 ; 95 \%$ confidence interval 0.04-0.7; $P=0.01$ ). Kaplan-Meier survival curves showed that survival rates at 30 days were $78.4 \%$ for the levosimendan group and $49.5 \%$ for the non-levosimendan group $(P=0.02)$. After propensity score matching analysis, the difference in 30-day mortality between the two groups was not significant (hazard ratio $=0.55 ; 95 \%$ confidence interval $0.27-1.10 ; P=0.09$ ).
\end{abstract}

Conclusions: Our results suggest that levosimendan was associated with a beneficial effect on VA-ECMO weaning in ICU patients.

Keywords: Extracorporeal membrane oxygenation, Levosimendan, Weaning, Mortality

\section{Introduction}

Venoarterial extracorporeal membrane oxygenation (VA-ECMO) is increasingly being used as a support system for patients with cardiogenic shock refractory to conventional medical therapies [1]. Levosimendan is a calcium-sensitizing inotropic agent that improves myocardial function in patients with cardiogenic shock [2]. Unlike other inotropes like dobutamine, levosimendan has anti-inflammatory properties and does not increase

\footnotetext{
${ }^{*}$ Correspondence: nicolas.allou@chu-reunion.fr

${ }^{5}$ Réanimation polyvalente, Hôpital Félix Guyon, Bellepierre, 97405 Saint-Denis, France

Full list of author information is available at the end of the article
}

myocardial oxygen consumption [3]. Nevertheless, debates continue in clinical practice regarding the beneficial effects of levosimendan in patients with cardiogenic shock or low cardiac output syndrome who are not treated with VA-ECMO [4-7]. While levosimendan has been shown to improve endothelial function and to increase cardiac index in cardiogenic shock patients undergoing VA-ECMO [8], few data are available on the impact of levosimendan in refractory cardiogenic shock patients undergoing VA-ECMO [9-11]. One study has suggested that levosimendan has beneficial effects on survival and VA-ECMO weaning, but only after cardiac surgery [10]. It may be that levosimendan should be administered only to specific cardiogenic shock patients, 
in particular those undergoing VA-ECMO. The aim of this study was to evaluate the impact of levosimendan on VA-ECMO weaning in patients hospitalized in intensive care unit (ICU).

\section{Materials and methods}

This study was approved by the Institutional Review Board of the Ethics Committee of the French Intensive Care Society (CE SRLF 18-03) and was declared to the Commission nationale de l'informatique et des libertés (CNIL MR-003, $\mathrm{N}^{\circ}$ 2000694). The need for informed consent was waived because of the observational and retrospective nature of the study.

\section{Selection of the study sample}

This retrospective cohort study was conducted between January 2010 and March 2017 in the 23-bed mixed medi$\mathrm{cal} /$ surgical ICU of a French university hospital.

All patients hospitalized in ICU undergoing VA-ECMO were consecutively evaluated. Exclusion criteria were: age $<18$ years, VA-ECMO duration $<2$ days and central VAECMO treatment.

During the study period, levosimendan and other catecholamines were administered at the physician's discretion to patients undergoing VA-ECMO. Levosimendan (12.5 mg diluted in $100 \mathrm{~mL}$ of $\mathrm{NaCl} 0.9 \%$ ) was administered without bolus as a continuous infusion at a dose of $0.2 \mu$ g per kilogram per minute during $24 \mathrm{~h}$.

For patients with mean arterial pressure above $65 \mathrm{mmHg}$ with pulsatile flow, VA-ECMO weaning was considered daily and VA-ECMO flow was gradually decreased to a minimum of 1-1.5 L/min. VA-ECMO was removed in patients meeting the following criteria: mean arterial pressure $>65 \mathrm{mmHg}$; low doses of administered catecholamine (norepinephrine $<0.1 \mu \mathrm{g} / \mathrm{kg} / \mathrm{min}$, dobutamine $<5 \mu \mathrm{g} / \mathrm{kg} / \mathrm{min}$ and no epinephrine); $\mathrm{PaO}_{2} /$ $\mathrm{FiO}_{2}$ ratio $>100 \mathrm{mmHg}$; left ventricular ejection fraction $>20 \%$; and aortic velocity-time integral $>12 \mathrm{~cm}[12,13]$.

\section{Data collection}

Data were collected on: age; gender; Simplified Acute Physiology Score 2; body mass index $>30 \mathrm{~kg} / \mathrm{m}^{2}$; previous coronary artery disease; hypertension; chronic renal failure with dialysis; chronic obstructive pulmonary disease; diabetes mellitus; history of congestive heart failure; immunosuppression (immunosuppressive disease, hematologic disease, treatment with immunosuppressive drugs within the previous 30 days, corticosteroid treatment with doses of at least $10 \mathrm{mg} /$ day of a prednisone equivalent for more than 2 weeks); liver cirrhosis; cancer; smoking (current or former); biochemical parameters; and organ failure at VA-ECMO cannulation.
After VA-ECMO cannulation, we collected data on: reason for initiation of VA-ECMO treatment; VA-ECMO flow $(\mathrm{L} / \mathrm{min})$; maximal dose of norepinephrine $(\mu \mathrm{g} / \mathrm{kg} /$ $\mathrm{min})$; maximal dose of dobutamine $(\mu \mathrm{g} / \mathrm{kg} / \mathrm{min})$; and presence or absence of an intra-aortic balloon pump.

In patients undergoing levosimendan treatment, echocardiographic measurements of aortic velocitytime integral and left ventricular ejection fraction were recorded just before levosimendan initiation and at the end of levosimendan infusion. Echocardiographic measurements were recorded with a VA-ECMO flow of $1 \mathrm{~L} /$ min and after interrupting intra-aortic balloon pump.

\section{Clinical definitions and study endpoints}

VA-ECMO weaning failure was defined as death during VA-ECMO treatment or as death within $24 \mathrm{~h}$ after VAECMO removal [10].

The primary endpoint was the impact of exposure to levosimendan on VA-ECMO weaning.

The secondary endpoint was the impact of exposure to levosimendan on mortality 30 days after VA-ECMO cannulation.

\section{Statistical analysis}

Results were expressed as frequencies and percentages for categorical variables, and as means and standard deviations for continuous variables. Prior to propensity score matching, continuous variables were compared using Student's $t$ test or the Mann-Whitney test, as appropriate. Qualitative variables were compared using Pearson's Chi-square or Fisher's exact test, as appropriate. Survival 30 days after VA-ECMO cannulation was estimated using the Kaplan-Meier method and compared using the logrank test.

The propensity score was defined as the probability of exposure to levosimendan. In order to limit overadjustment due to the use of this score [14], we selected only the covariates most likely to introduce a confounding bias [15]. The propensity score was estimated using a logistic regression adjusted for age, sex, indication for VA-ECMO, VA duration, presence of a history of heart failure, body mass index $>30 \mathrm{~kg} / \mathrm{m}^{2}$, Glasgow Coma Scale score on admission and presence of high blood pressure. Matching was then performed between one patient exposed to levosimendan and up to two unexposed patients [16], with a propensity score caliper of 0.05 .

After propensity score matching, standardized differences were estimated to compare baseline characteristics and to therefore assess the accuracy of the matching procedure. Associations between outcomes and covariates were assessed using bivariate conditional Cox models stratified by the risk set defined with the propensity score 
matching procedure. Hazard ratios (HR) and their 95\% confidence intervals were calculated.

A two-tailed $p$ value $<0.05$ was considered significant. Analyses were performed using SAS statistical software (9.4, SAS Institute, Cary, NC, USA).

\section{Results}

\section{Study population}

Over the study period, 201 patients underwent VAECMO treatment. Among these, 51 patients were excluded from the study $(7$ were $<18$ years, 20 received VA-ECMO for $<2$ days, and 24 were treated with central VA-ECMO). A total of 150 patients supported using peripheral VA-ECMO were eligible for the study.

In 2010-2011, in 2012-2013, in 2014-2015 and in 2016-2017, two out of 10 patients (20\%), 17 out of $52(32.7 \%), 23$ out $63(36.5 \%)$ and 9 out 25 (36\%) were, respectively, treated with levosimendan.

Thirty-eight propensity-matched patients were evaluated in the levosimendan group and 65 in the non-levosimendan group (Fig. 1).

\section{Characteristics and outcome of the 150 pre-matched patients}

Table 1 presents the characteristics of the 150 patients on ICU admission and on study inclusion (prior to matching). Mean age was $53.4 \pm 15$ years, and median Simplified Acute Physiology Score 2 on admission was $59.2 \pm 19.7$ (Table 1). During the study period, 51 patients were treated with levosimendan (34\%). Main indications for initiation of VA-ECMO treatment were post-cardiotomy cardiogenic shock in 49 cases $(32.7 \%)$ and postacute myocardial infarction cardiogenic shock in 44 cases (29.3\%). VA-ECMO cannulation site was femoro-femoral in 147 cases (97\%), and an intra-aortic balloon pump was present in 42 cases (28\%).

The proportion of patients with a history of congestive heart failure ( $33.3 \%$ vs. $18.2 \%, P=0.04)$ was higher in the levosimendan group than in the non-levosimendan group. Reasons for VA-ECMO initiation varied between the two groups $(P=0.024)$ (Table 1$)$.

Levosimendan was administered after $3.2 \pm 2.8$ days after VA-ECMO cannulation. In patients treated with levosimendan, left ventricular ejection fraction increased from $21.5 \pm 9.1 \%$ to $30.7 \pm 13.5 \%(P<0.0001)$ and aortic velocity-time integral increased from $8.9 \pm 4 \mathrm{~cm}$ to $12.5 \pm 3.8 \mathrm{~cm},(P=0.002)$. Out of 150 patients, 103 were weaned from VA-ECMO (68.7\%): 42 (82.4\%) in the levosimendan group versus $61(61.6 \%)$ in the non-levosimendan group $(P=0.01)$.

Kaplan-Meier survival curves showed that survival rate at 30 days was $78.4 \%$ in the levosimendan group and $49.5 \%$ in the non-levosimendan group $(P=0.02)$ (Fig. 2$)$.

\section{Characteristics and outcome of the 103 matched patients}

After propensity score matching, no significant differences were found in the characteristics of patients between the levosimendan group and the non-levosimendan group (Table 2).

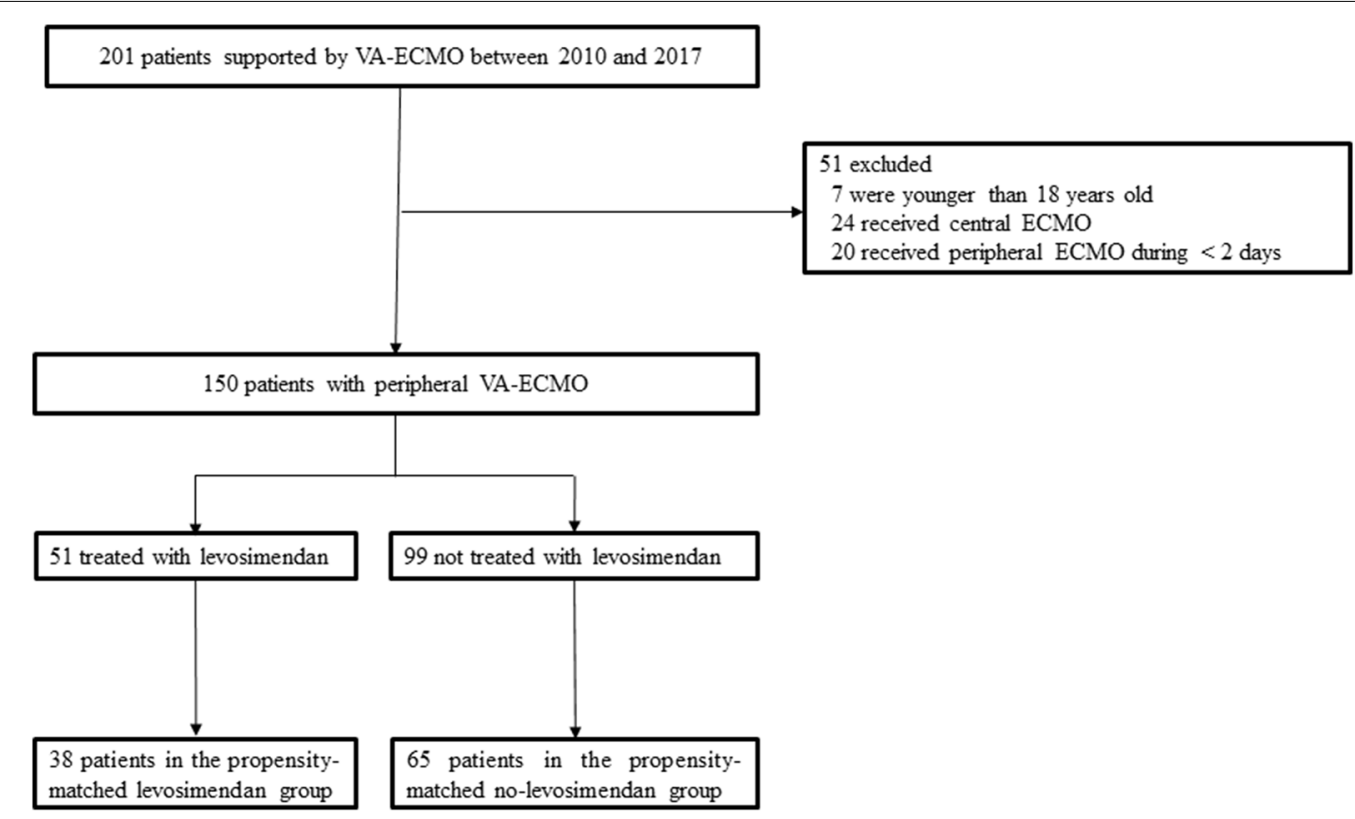

Fig. 1 Selection of the study sample 
Table 1 Baseline patient characteristics in pre-matched groups

\begin{tabular}{|c|c|c|c|c|}
\hline \multirow[t]{2}{*}{ Variables } & \multirow{2}{*}{$\begin{array}{l}\text { Total } \\
(n=150)\end{array}$} & \multicolumn{2}{|c|}{ Levosimendan } & \multirow[t]{2}{*}{$P$ value } \\
\hline & & Yes $(n=51)$ & No $(n=99)$ & \\
\hline Length of stay in hospital before VA-ECMO (days) & $5.1 \pm 8.6$ & $6.4 \pm 8.5$ & $4.4 \pm 8.5$ & 0.18 \\
\hline Length of stay in ICU before VA-ECMO (days) & $1.1 \pm 4.1$ & $0.6 \pm 1.6$ & $1.3 \pm 4.9$ & 0.16 \\
\hline \multicolumn{5}{|l|}{ Clinical characteristics at ICU admission } \\
\hline Simplified Acute Physiology Score 2 & $59.2 \pm 19.7$ & $55.5 \pm 19.6$ & $61 \pm 19.5$ & 0.1 \\
\hline Male & $98(65.3)$ & $36(70.6)$ & $62(62.6)$ & 0.37 \\
\hline Age (years) & $53.4 \pm 15$ & $53.6 \pm 15.4$ & $53.2 \pm 14.9$ & 0.87 \\
\hline Body mass index $>30 \mathrm{~kg} / \mathrm{m}^{2}$ & $33(22)$ & $8(15.7)$ & $25(25.3)$ & 0.22 \\
\hline Previous coronary artery disease & $44(29.3)$ & $17(33.3)$ & $27(27.3)$ & 0.45 \\
\hline Hypertension & $65(43.3)$ & $20(39.2)$ & $45(45.5)$ & 0.49 \\
\hline Chronic renal failure with dialysis & $15(10)$ & $6(11.8)$ & $9(9.1)$ & 0.78 \\
\hline Chronic obstructive pulmonary disease & $8(5.3)$ & $3(5.9)$ & $5(5.1)$ & 1 \\
\hline Diabetes mellitus & $54(36)$ & $19(37.3)$ & $35(35.4)$ & 0.86 \\
\hline History of congestive heart failure & $35(23.3)$ & $17(33.3)$ & $18(18.2)$ & 0.04 \\
\hline Immunosuppression & $5(3.3)$ & $2(3.9)$ & $3(3)$ & 1 \\
\hline Liver cirrhosis & $3(2)$ & $2(3.9)$ & $1(1)$ & 0.27 \\
\hline Cancer & $1(0.7)$ & 0 & $1(1)$ & 1 \\
\hline Smoking (current or former) & $47(31.3)$ & $17(33.3)$ & $30(30.3)$ & 0.71 \\
\hline Hazardous alcohol use & $30(20)$ & $11(21.6)$ & $19(19.2)$ & 0.83 \\
\hline Glasgow Coma Scale score & $12.7 \pm 4.6$ & $13.8 \pm 3.6$ & $12.2 \pm 4.9$ & 0.029 \\
\hline Catecholamines & $149(99.3)$ & $51(100)$ & $98(99)$ & 1 \\
\hline Mechanical ventilation & $137(91.3)$ & $47(92.2)$ & $90(90.9)$ & 1 \\
\hline Renal replacement therapy & $61(40.7)$ & $20(39.2)$ & $41(41.4)$ & 0.86 \\
\hline Total bilirubin level ( $\mu \mathrm{mol} / \mathrm{L})$ & $31.6 \pm 39.8$ & $35.5 \pm 50.8$ & $29.6 \pm 32.9$ & 0.49 \\
\hline Platelet count (G/L) & $154 \pm 93$ & $160 \pm 107$ & $151 \pm 85$ & 0.56 \\
\hline Prothrombin (\%) & $47.5 \pm 20$ & $50.3 \pm 16.8$ & $46.1 \pm 21.4$ & 0.22 \\
\hline Hemoglobin level (g/dL) & $10.3 \pm 7.5$ & $11.5 \pm 12.5$ & $9.6 \pm 2.3$ & 0.16 \\
\hline Creatinine level $(\mu \mathrm{mol} / \mathrm{L})$ & $172 \pm 138$ & $173 \pm 131$ & $171 \pm 143$ & 0.45 \\
\hline Left ventricular ejection fraction (\%) & $19.9 \pm 6.7$ & $19.1 \pm 6.8$ & $20.3 \pm 6.6$ & 0.36 \\
\hline \multicolumn{4}{|l|}{ Reason for VA-ECMO } & 0.024 \\
\hline Cardiac arrest & $4(2.7)$ & $2(3.9)$ & $2(2)$ & \\
\hline Dilated cardiomyopathy & $10(6.7)$ & $5(9.8)$ & $5(5.1)$ & \\
\hline Myocarditis & $7(4.7)$ & $1(2)$ & $6(6.1)$ & \\
\hline Acute myocardial infarction & $44(29.3)$ & $14(27.5)$ & $30(30.3)$ & \\
\hline Post-cardiotomy & $49(32.7)$ & $24(47.1)$ & $25(25.3)$ & \\
\hline Acute respiratory distress syndrome & $3(2)$ & 0 & $3(3)$ & \\
\hline Percutaneous implantation of VA-ECMO & $66(44)$ & $21(41.2)$ & $45(45.5)$ & 0.73 \\
\hline \multicolumn{5}{|l|}{ Hemodynamic parameters (first $24 \mathrm{~h}$ post-VA-ECMO) } \\
\hline VA-ECMO flow (L/min) & $3.65 \pm 0.62$ & $3.87 \pm 0.69$ & $3.59 \pm 0.61$ & 0.29 \\
\hline Maximal dose of norepinephrine ( $\mu \mathrm{g} / \mathrm{kg} / \mathrm{min})$ & $0.74 \pm 0.69$ & $0.74 \pm 0.62$ & $0.74 \pm 0.72$ & 0.62 \\
\hline Maximal dose of Dobutamine ( $\mathrm{gg} / \mathrm{kg} / \mathrm{min})$ & $10.1 \pm 4.3$ & $10.7 \pm 4.5$ & $9.8 \pm 4.2$ & 0.32 \\
\hline Intra-aortic balloon pump & $42(28)$ & $16(31.4)$ & $26(26.3)$ & 0.32 \\
\hline VA-ECMO duration (day) & $11.6 \pm 11$ & $12.3 \pm 11.8$ & $11.2 \pm 10.6$ & 0.23 \\
\hline
\end{tabular}

Results are expressed as mean \pm SD or number (\%)

VA-ECMO venoarterial extracorporeal membrane oxygenation, ICU intensive care unit

Out of 103 patients, 73 were successfully weaned from VA-ECMO (70.9\%). After propensity score matching, exposure to levosimendan was the only remaining factor associated with a significant reduction in VA-ECMO weaning failure rates (hazard ratio $=0.16 ; 95 \%$ confidence interval: 0.04-0.70; $P=0.01$ ) (Table 3). 


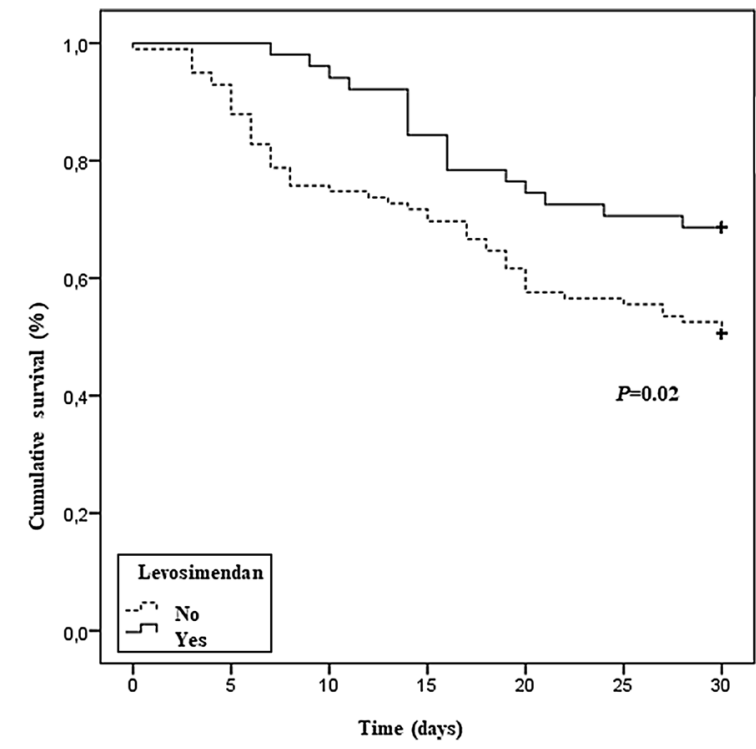

Fig. 2 Survival rate for patients with or without levosimendan by Kaplan-Meier analysis

The use of levosimendan tended to decrease 30-day mortality after propensity score matching; however, the difference in 30-day mortality between the two groups was not significant (hazard ratio $=0.55 ; 95 \%$ confidence interval: $0.27-1.10 ; P=0.09$ ). The other factors found to be associated with 30-day mortality were higher Simplified Acute Physiology Score $2(P=0.002)$, higher age $(P=0.01)$ and reason for VA-ECMO $(P=0.01)$.

\section{Discussion}

This retrospective study suggests that levosimendan might be associated with beneficial effects on peripheral VA-ECMO weaning in patients hospitalized in ICU. The decrease in mortality did not reach statistical significance $(P=0.09)$ among propensity-matched patients.

To our knowledge, two other studies have evaluated the impact of levosimendan on VA-ECMO weaning [10, 11]. This first study, conducted by Distelmaier et al. [9], also found a beneficial effect of levosimendan, but it was restricted to patients treated with the drug after cardiac surgery [9].

The second retrospective study by Jacky et al. was also restricted to cardiac surgery patients and compared levosimendan to milrinone without finding any significant difference between the two treatments [11]. By contrast, all patients undergoing peripheral VA-ECMO were included in our analysis, including those who did not undergo cardiac surgery. In our view, extending the study population to non-cardiac surgery patients is relevant for physicians in the field because cardiac surgery is not the only indication for VA-ECMO. Indeed, in both our study and the Extracorporeal Life Support Organization Registry, over $50 \%$ of patients had medical indication for VA-ECMO [17].

Studies have shown that the incidence of severe complications like cannula-related infection [18], severe bleeding [19] and thromboembolic event [20] is associated with longer VA-ECMO duration. The use of levosimendan in patients undergoing VA-ECMO may therefore be of interest both to reduce the duration of mechanical support and to minimize severe complications.

In addition to its hemodynamic actions, another hypothesis for the beneficial effects of levosimendan may be its positive protective effects on endothelium function, particularly in inflammatory situations [21,22]. This is relevant to VA-ECMO treatment [8], which has been shown to be associated with endothelial damage and pro-inflammatory effects $[23,24]$. Thus, in a preliminary observational study, Sangalli et al. [8] found that infusion of levosimendan leads to significant improvement in endothelial function, cardiac index and mixed venous oxygen saturation in adult cardiogenic shock patients with low ejection supported using VA-ECMO. They concluded that levosimendan facilitates weaning from extracorporeal support.

In our study, a nonsignificant decrease in mortality was found after propensity score matching. However, this lack of significance may be due to a lack of power, as only 103 patients were ultimately evaluated. By contrast, the study by Distelmaier et al. found an association between levosimendan treatment and improved survival in patients undergoing VA-ECMO after cardiac surgery [10].

A large study evaluating 5263 patients treated with VA-ECMO found that $64.4 \%$ of these patients were successfully weaned from extracorporeal support. However, VA-ECMO weaning did not necessarily result in survival, as in-hospital mortality in weaned patients was over $38 \%$ [25].

The beneficial effects of levosimendan are still debated in clinical practice [5-7]. In two meta-analyses of randomized studies evaluating patients after cardiac surgery, levosimendan was shown to have a greater effect on mortality in patients with impaired left ventricular systolic function than in those with preserved left ventricular systolic function [26, 27]. Moreover, randomized controlled trials found that the use of levosimendan was not associated with beneficial effects on duration of mechanical ventilation, ICU length of stay or mortality $[6,28]$. It may be that levosimendan should be administered only to specific cardiogenic shock patients, in particular those 
Table 2 Patient characteristics in propensity-matched groups

\begin{tabular}{|c|c|c|c|}
\hline \multirow[t]{2}{*}{ Variables } & \multicolumn{2}{|c|}{ Levosimendan group } & \multirow{2}{*}{$\begin{array}{l}\text { Standardized } \\
\text { difference }\end{array}$} \\
\hline & Yes $(n=38)$ & No $(n=65)$ & \\
\hline Length of stay in hospital before VA-ECMO (days) & $4.7 \pm 6.7$ & $5.4 \pm 9.7$ & -0.09 \\
\hline Length of stay in ICU before VA-ECMO (days) & $0.5 \pm 1.8$ & $1.7 \pm 5.5$ & -0.29 \\
\hline \multicolumn{4}{|l|}{ Clinical characteristics at ICU admission } \\
\hline Simplified Acute Physiology Score 2 & $58.3 \pm 18.1$ & $58.1 \pm 19.4$ & 0.01 \\
\hline Male & $26(68.4)$ & $46(70.8)$ & -0.05 \\
\hline Age (years) & $53.8 \pm 15.4$ & $54.2 \pm 14.5$ & -0.03 \\
\hline Body mass index $>30 \mathrm{~kg} / \mathrm{m}^{2}$ & $8(21.1)$ & $13(20.0)$ & 0.03 \\
\hline Previous coronary artery disease & $17(44.7)$ & $17(26.2)$ & 0.39 \\
\hline Hypertension & $15(39.5)$ & $29(44.6)$ & -0.10 \\
\hline Chronic renal failure with dialysis & $6(15.8)$ & $8(12.3)$ & 0.10 \\
\hline Chronic obstructive pulmonary disease & $3(7.9)$ & $5(7.7)$ & 0.01 \\
\hline Diabetes mellitus & $17(44.7)$ & $21(32.3)$ & 0.25 \\
\hline History of congestive heart failure & $9(23.7)$ & $13(20.0)$ & 0.09 \\
\hline Immunosuppression & $1(2.6)$ & $1(1.5)$ & 0.08 \\
\hline Liver cirrhosis & $1(2.6)$ & $1(1.5)$ & 0.08 \\
\hline Cancer & 0 & 0 & 0.00 \\
\hline Smoking (current or former) & $12(31.6)$ & $24(36.9)$ & -0.11 \\
\hline Hazardous alcohol use & $8(21.1)$ & $13(20.0)$ & 0.03 \\
\hline Glasgow Coma Scale score & $13.7 \pm 3.7$ & $13.4 \pm 3.9$ & 0.08 \\
\hline Catecholamines & $38(100.0)$ & $64(98.5)$ & 0.18 \\
\hline Mechanical ventilation & $36(94.7)$ & $57(87.7)$ & 0.25 \\
\hline Renal replacement therapy & $17(44.7)$ & $29(44.6)$ & 0.00 \\
\hline Total bilirubin level ( $\mu \mathrm{mol} / \mathrm{L})$ & $35.1 \pm 50.6$ & $32.7 \pm 37.3$ & 0.05 \\
\hline Platelet count (G/L) & $169.4 \pm 116.0$ & $144.5 \pm 89.9$ & 0.24 \\
\hline Prothrombin (\%) & $51.1 \pm 16.1$ & $45.4 \pm 22.3$ & 0.29 \\
\hline Hemoglobin level (g/dL) & $12.2 \pm 14.4$ & $9.7 \pm 2.4$ & 0.25 \\
\hline Creatinine level ( $\mu \mathrm{mol} / \mathrm{L})$ & $182.0 \pm 149.5$ & $181.7 \pm 165.2$ & 0.00 \\
\hline Left ventricular ejection fraction (\%) & $19.6 \pm 6.8$ & $20.6 \pm 6.8$ & -0.14 \\
\hline Reason for VA-ECMO & & & 0.24 \\
\hline Cardiac arrest & $1(2.6)$ & $2(3.1)$ & \\
\hline Dilated cardiomyopathy & $4(10.5)$ & $5(7.7)$ & \\
\hline Myocarditis & $1(2.6)$ & $4(6.1)$ & \\
\hline Acute myocardial infarction & $13(34.2)$ & $18(27.7)$ & \\
\hline Post-cardiotomy & $14(36.9)$ & $24(36.9)$ & \\
\hline Other reason & $5(13.2)$ & $12(18.5)$ & \\
\hline Percutaneous implantation of VA-ECMO & $18(47.4)$ & $27(41.5)$ & 0.12 \\
\hline \multicolumn{4}{|l|}{ Hemodynamic parameters (first $24 \mathrm{~h}$ post-VA-ECMO) } \\
\hline VA-ECMO flow (L/min) & $3.7 \pm 0.6$ & $3.5 \pm 0.6$ & 0.25 \\
\hline Maximal dose of norepinephrine ( $\mu \mathrm{g} / \mathrm{kg} / \mathrm{min})$ & $0.7 \pm 0.6$ & $0.7 \pm 0.6$ & 0.04 \\
\hline Maximal dose of Dobutamine ( $\mu \mathrm{g} / \mathrm{kg} / \mathrm{min})$ & $10.8 \pm 4.3$ & $9.9 \pm 3.6$ & 0.23 \\
\hline Intra-aortic balloon pump & $15(39.5)$ & $17(26.2)$ & 0.28 \\
\hline VA-ECMO duration & $11.9 \pm 8.1$ & $10.7 \pm 8$ & 0.15 \\
\hline
\end{tabular}

Results are expressed as mean \pm SD or number (\%)

VA-ECMO venoarterial extracorporeal membrane oxygenation, ICU intensive care unit 
Table 3 Factors associated with VA-ECMO weaning after propensity score matching

\begin{tabular}{|c|c|c|c|}
\hline Variables & Success $(n=73)$ & Failure $(n=30)$ & $P$-value \\
\hline Length of stay in hospital before VA-ECMO (day) & $5.6 \pm 8.5$ & $3.9 \pm 9.1$ & 0.35 \\
\hline Length of stay in ICU before VA-ECMO (day) & $1.4 \pm 5.1$ & $0.7 \pm 1.1$ & 0.19 \\
\hline \multicolumn{4}{|l|}{ Clinical characteristics at ICU admission } \\
\hline Simplified Acute Physiology Score 2 & $56.6 \pm 19.0$ & $62.1 \pm 18.2$ & 0.18 \\
\hline Male & $50(68.5)$ & $22(73.3)$ & 0.63 \\
\hline Age (years) & $52.5 \pm 15.8$ & $57.9 \pm 11.1$ & 0.09 \\
\hline Body mass index $>30 \mathrm{~kg} / \mathrm{m}^{2}$ & $13(17.8)$ & $8(26.7)$ & 0.31 \\
\hline Previous coronary artery disease & $22(30.1)$ & $12(40.0)$ & 0.33 \\
\hline Hypertension & $27(37.0)$ & $17(56.7)$ & 0.07 \\
\hline Chronic renal failure with dialysis & $10(13.7)$ & $4(13.3)$ & 1.00 \\
\hline Chronic obstructive pulmonary disease & $4(5.5)$ & $4(13.3)$ & 0.23 \\
\hline Diabetes mellitus & $23(31.5)$ & $15(50.0)$ & 0.08 \\
\hline History of congestive heart failure & $18(24.7)$ & $4(13.3)$ & 0.2 \\
\hline Immunosuppression & $2(2.7)$ & $0(0.0)$ & 1.0 \\
\hline Liver cirrhosis & $2(2.7)$ & $0(0.0)$ & 1.00 \\
\hline Cancer & 0 & 0 & 1 \\
\hline Smoking (current or former) & $24(32.9)$ & $12(40.0)$ & 0.49 \\
\hline Hazardous alcohol use & $14(19.2)$ & $7(23.3)$ & 0.63 \\
\hline Glasgow Coma Scale score & $13.6 \pm 3.8$ & $13.3 \pm 4.1$ & 0.73 \\
\hline Catecholamines & $72(98.6)$ & $30(100.0)$ & 1.00 \\
\hline Mechanical ventilation & $65(89.0)$ & $28(93.3)$ & 0.72 \\
\hline Renal replacement therapy & $31(42.5)$ & $15(50.0)$ & 0.48 \\
\hline Total bilirubin level ( $\mu \mathrm{mol} / \mathrm{L})$ & $35.9 \pm 44.2$ & $28.0 \pm 37.8$ & 0.39 \\
\hline Platelet count (G/L) & $152.3 \pm 102.8$ & $157.1 \pm 96.2$ & 0.82 \\
\hline Prothrombin (\%) & $49.3 \pm 21.4$ & $43.3 \pm 17.2$ & 0.18 \\
\hline Hemoglobin level (g/dL) & $10.9 \pm 10.6$ & $9.9 \pm 2.1$ & 0.59 \\
\hline Creatinine level ( $\mu \mathrm{mol} / L)$ & $173.8 \pm 138.4$ & $201.4 \pm 201.5$ & 0.43 \\
\hline Left ventricular ejection fraction (\%) & $20.2 \pm 6.5$ & $20.3 \pm 7.4$ & 0.97 \\
\hline Reason for VA-ECMO & & & 0.28 \\
\hline Cardiac arrest & $1(1.4)$ & $2(6.7)$ & \\
\hline Dilated cardiomyopathy & $8(11.0)$ & $1(3.3)$ & \\
\hline Myocarditis & $5(6.8)$ & $0(0.0)$ & \\
\hline Acute myocardial infarction & $20(27.4)$ & $11(36.7)$ & \\
\hline Post-cardiotomy & $28(38.4)$ & $10(33.3)$ & \\
\hline Other reason & $11(15.1)$ & $6(20.0)$ & \\
\hline Percutaneous implantation of VA-ECMO & $34(46.6)$ & $11(36.7)$ & 0.36 \\
\hline \multicolumn{4}{|l|}{ Hemodynamic parameters (first 24 h post-VA-ECMO) } \\
\hline VA-ECMO flow (L/min) & $3.5 \pm 0.6$ & $3.6 \pm 0.5$ & 0.51 \\
\hline Maximal dose of norepinephrine ( $\mu \mathrm{g} / \mathrm{kg} / \mathrm{min})$ & $0.8 \pm 0.6$ & $0.6 \pm 0.6$ & 0.15 \\
\hline Maximal dose of dobutamine ( $\mu \mathrm{g} / \mathrm{kg} / \mathrm{min})$ & $10.1 \pm 3.7$ & $10.4 \pm 4.5$ & 0.69 \\
\hline Intra-aortic balloon pump & $24(32.9)$ & $8(26.7)$ & 0.54 \\
\hline VA-ECMO duration & $11.9 \pm 8.8$ & $9.3 \pm 5.4$ & 0.14 \\
\hline Levosimendan & $32(43.8)$ & $6(20.0)$ & 0.01 \\
\hline
\end{tabular}

Results are expressed as mean \pm SD or number (\%)

VA-ECMO venoarterial extracorporeal membrane oxygenation, ICU intensive care unit 
undergoing VA-ECMO. Levosimendan may be associated with favorable outcome-including reduced mortality-in patients with very low left ventricular ejection fraction.

\section{Limitations}

Our study has several limitations. The retrospective nature of the analysis is clearly a weakness. In addition, our study may suffer from a lack of power because of the low number of patients and events evaluated. The main limitation of our study is that administration of levosimendan was not randomized. However, to limit biases due to the absence of randomization, we used a multivariate logistic regression model with a propensity score analysis. Although several definitions of VA-ECMO weaning success have been proposed $[11,29,30]$, we adopted the definition used in the recent study by Distelmeier et al. [10]. Aortic velocity-time integral and left ventricular ejection fraction were not collected in the control group. And it is possible that $24 \mathrm{~h}$ of mechanical support provide some improvement in aortic velocitytime integral even in the absence of levosimendan. The timing of levosimendan administration with respect to VA-ECMO initiation was variable, and so, the time, the conditions and the optimum conditions for introducing this treatment in this context remain to be established. As in the study Distelmaier et al. [10], the preparation used for levosimendan $(0.125 \mathrm{mg} / \mathrm{mL})$ was not the one recommended for levosimendan administration $(<0.05 \mathrm{mg} / \mathrm{mL})$ [31] and that may have resulted in potential inhomogeneity of the drug delivery with medication precipitation.

\section{Conclusion}

This study suggests that levosimendan might be associated with a beneficial effect on VA-ECMO weaning in ICU patients. The difference in mortality among propensity-matched patients failed to reach statistical significance.

\section{Abbreviations \\ VA-ECMO: venoarterial extracorporeal membrane oxygenation; ICU: intensive care unit.}

\section{Authors' contributions}

AN and SV had full access to all of the data in the study and take responsibility for the integrity of the data and the accuracy of the data analysis. NA, SV, JAA and CF conceptualized and designed the study. SV, RP, BB, EB, HLP, OM, DV and TA were involved in acquisition of data. NA, SV, RP, BB, EB, HLP, OM, DV, TA and JA analyzed and interpreted the data. SV, RP, BB, EB, HLP, OM, DV, TA and JA drafted the manuscript. SV, CF, RP, BB, EB, HLP, OM, DV, TA and JA critically revised the manuscript for important intellectual content. CF and JA carried out the statistical analysis. Funding support was provided solely from institutional and/or departmental sources. SV, CF, RP, BB, EB, HLP, OM, DV, TA and JA were involved in administrative, technical or material support. SV, CF, RP, BB, EB,
HLP, OM, DV, TA and JA supervised the study. All authors read and approved the final manuscript.

\section{Author details}

${ }^{1}$ Réanimation polyvalente, Centre Hospitalier Universitaire Félix Guyon, 97405 Saint-Denis, Allée des Topazes, France. ${ }^{2}$ Unité de Soutien Méthodologique, CHU de La Réunion, Saint-Denis, France. ${ }^{3}$ INSERM, CIC 1410, Saint-Pierre, France. ${ }^{4}$ Chirurgie cardiaque, Centre Hospitalier Universitaire Félix Guyon, 97405 Saint-Denis, Allée des Topazes, France. ${ }^{5}$ Réanimation polyvalente, Hôpital Félix Guyon, Bellepierre, 97405 Saint-Denis, France.

\section{Acknowledgements}

Not applicable.

\section{Competing interests}

The authors declare that they have no competing interests.

\section{Availability of data and materials}

The data used and/or analyzed in the present study are available from the corresponding author on reasonable request.

\section{Consent for publication \\ Not applicable.}

\section{Ethics approval and consent to participate}

This study was approved by the Institutional Review Board of the Ethics Committee of the French Intensive Care Society (CE SRLF 18-03) and was declared to the Commission nationale de l'informatique et des liberté (CNIL MR-003, Nº 2000694). The need for informed consent was waived because of the observational and retrospective nature of the study.

\section{Funding}

This work was internally funded.

\section{Publisher's Note}

Springer Nature remains neutral with regard to jurisdictional claims in published maps and institutional affiliations.

Received: 14 November 2018 Accepted: 29 January 2019

Published online: 01 February 2019

\section{References}

1. Sauer CM, Yuh DD, Bonde P. Extracorporeal membrane oxygenation use has increased by 433\% in adults in the United States from 2006 to 2011. ASAIO J. 2015;61:31-6.

2. Russ MA, Prondzinsky R, Christoph A, Schlitt A, Buerke U, Söffker G, et al. Hemodynamic improvement following levosimendan treatment in patients with acute myocardial infarction and cardiogenic shock. Crit Care Med. 2007:35:2732-9.

3. Parissis JT, Adamopoulos S, Antoniades C, Kostakis G, Rigas A, Kyrzopoulos $\mathrm{S}$, et al. Effects of levosimendan on circulating pro-inflammatory cytokines and soluble apoptosis mediators in patients with decompensated advanced heart failure. Am J Cardiol. 2004;93:1309-12.

4. Koster G, Wetterslev J, Gluud C, Zijlstra JG, Scheeren TW, van der Horst IC, et al. Effects of levosimendan for low cardiac output syndrome in critically ill patients: systematic review with meta-analysis and trial sequential analysis. Intensive Care Med. 2015;41:203-21.

5. Sanfilippo F, Knight JB, Scolletta S, Santonocito C, Pastore F, Lorini FL, et al. Levosimendan for patients with severely reduced left ventricular systolic function and/or low cardiac output syndrome undergoing cardiac surgery: a systematic review and meta-analysis. Crit Care. 2017;21:252.

6. Landoni G, Lomivorotov VV, Alvaro G, Lobreglio R, Pisano A, Guarracino $\mathrm{F}$, et al. Levosimendan for hemodynamic support after cardiac surgery. N Engl J Med. 2017;376:2021-31.

7. Mehta RH, Leimberger JD, van Diepen S, Meza J, Wang A, Jankowich R, et al. Levosimendan in patients with left ventricular dysfunction undergoing cardiac surgery. N Engl J Med. 2017;376:2032-42. 
8. Sangalli F, Avalli L, Laratta M, Formica F, Maggioni E, Caruso R, et al. Effects of levosimendan on endothelial function and hemodynamics during weaning from venoarterial extracorporeal life support. J Cardiothorac Vasc Anesth. 2016;30:1449-53.

9. Affronti A, Di Bella I, Carino D, Ragni T. Levosimendan may improve weaning outcomes in venoarterial ECMO patients. ASAIO J. 2013;59:554-7.

10. Distelmaier K, Roth C, Schrutka L, Binder C, Steinlechner B, Heinz G, et al Beneficial effects of levosimendan on survival in patients undergoing extracorporeal membrane oxygenation after cardiovascular surgery. Br J Anaesth. 2016;117:52-8.

11. Jacky A, Rudiger A, Krüger B, Wilhelm MJ, Paal S, Seifert B, et al. Comparison of levosimendan and milrinone for ECLS weaning in patients after cardiac surgery - a retrospective before-and-after study. J Cardiothorac Vasc Anesth. 2018;32:2112-9.

12. Aissaoui N, Luyt CE, Leprince P, Trouillet JL, Léger P, Pavie A, et al. Predictors of successful extracorporeal membrane oxygenation (ECMO) weaning after assistance for refractory cardiogenic shock. Intensive Care Med. 2011;37:1738-45.

13. Donker DW, Meuwese CL, Braithwaite SA, Broomé M, van der Heijden JJ, Hermens JA, et al. Echocardiography in extracorporeal life support: a key player in procedural guidance, tailoring and monitoring. Perfusion. 2018:33:31-41.

14. Schuster T, Lowe WK, Platt RW. Propensity score model overfitting led to inflated variance of estimated odds ratios. J Clin Epidemiol. 2016;80:97-106.

15. Brookhart MA, Schneeweiss S, Rothman KJ, Glynn RJ, Avorn J, Stürmer $\mathrm{T}$, et al. Variable selection for propensity score models. Am J Epidemiol. 2006;163:1149-56.

16. Rassen JA, Shelat AA, Myers J, Glynn RJ, Rothman KJ, Schneeweiss S. One-to-many propensity score matching in cohort studies. Pharmacoepidemiol Drug Saf. 2012;21(S2):69-80.

17. Smith M, Vukomanovic A, Brodie D, Thiagarajan R, Rycus P, Buscher $H$, et al. Duration of venoarterial extracorporeal life support (VA ECMO) and outcome: an analysis of the Extracorporeal Life Support Organization (ELSO) registry. Crit Care. 2017:6(21):45.

18. Allou N, Lo Pinto H, Persichini R, Bouchet B, Braunberger E, Lugagne $\mathrm{N}$, et al. Cannula-related infection in patients supported by peripheral ECMO: clinical and microbiological characteristics. ASAIO J. 2018. https:// doi.org/10.1097/mat.0000000000000771.

19. Aubron C, DePuydt J, Belon F, Bailey M, Schmidt M, Sheldrake J, et al. Predictive factors of bleeding events in adults undergoing extracorporeal membrane oxygenation. Ann Intensive Care. 2016;6(1):97.

20. Trudzinski FC, Minko P, Rapp D, Fähndrich S, Haake H, Haab M, et al. Runtime and aPTT predict venous thrombosis and thromboembolism in patients on extracorporeal membrane oxygenation: a retrospective analysis. Ann Intensive Care. 2016;6(1):66.

21. Farmakis D, Alvarez J, Gal TB, Brito D, Fedele F, Fonseca C, et al. Levosimendan beyond inotropy and acute heart failure: evidence of pleiotropic effects on the heart and other organs: an expert panel position paper. Int J Cardiol. 2016;222:303-12.

22. Grossini E, Molinari C, Caimmi PP, Uberti F, Vacca G. Levosimendan induces NO production through p38 MAPK, ERK and Akt in porcine coronary endothelial cells: role for mitochondrial K(ATP) channel. $\mathrm{Br}$ J Pharmacol. 2009;156:250-61.

23. Ingyinn M, Lee J, Short BL, Viswanathan M. Venoarterial extracorporeal membrane oxygenation impairs basal nitric oxide production in cerebral arteries of newborn lambs. Pediatr Crit Care Med. 2000;1:161-5 (Crit Care. 2016 Nov 28;20(1):387)

24. Millar JE, Fanning JP, McDonald Cl, McAuley DF, Fraser JF. The inflammatory response to extracorporeal membrane oxygenation (ECMO): a review of the pathophysiology. Crit Care. 2016;20(1):387.

25. Aso S, Matsui H, Fushimi K, Yasunaga H. In-hospital mortality and successful weaning from venoarterial extracorporeal membrane oxygenation: analysis of 5263 patients using a national inpatient database in Japan. Crit Care. 2016;5(20):80

26. Harrison RW, Hasselblad V, Mehta RH, Levin R, Harrington RA, Alexander $\mathrm{JH}$, et al. Effect of levosimendan on survival and adverse events after cardiac surgery: a meta-analysis. J Cardiothorac Vasc Anesth. 2013;27:1224-32

27. Qiang H, Luo X, Huo JH, Wang ZQ. Perioperative use of levosimendan improves clinical outcomes in patients after cardiac surgery: a systematic review and meta-analysis. J Cardiovasc Pharmacol. 2018;72:11-8.

28. Cholley B, Carbura T, Grosjean S, Amour J, Ouattara A, Villacorta J, Miguet, et al. Effect of levosimendan on low cardiac output syndrome in patients with low ejection fraction undergoing coronary artery bypass grafting with cardiopulmonary bypass: the LICORN randomized clinical trial. JAMA. 2017;318:548-56.

29. Akin S, Dos Reis MirandaD, Caliskan K, Soliman Ol, Guven G, Struijs A, et al. Functional evaluation of sublingual microcirculation indicates successful weaning from VA-ECMO in cardiogenic shock. Crit Care. 2017;21(1):265.

30. Lee W, Kim Y, Choi H, Kim H, Lee S, Lee H, Chee H, et al. Advanced age as a predictor of survival and weaning in venoarterial extracorporeal oxygenation: a retrospective observational study. Biomed Res Int. 2017;2017:3505784

31. https://www.vidal.fr/Medicament/zimino-164292.htm.

\section{Submit your manuscript to a SpringerOpen ${ }^{\odot}$ journal and benefit from:}

- Convenient online submission

- Rigorous peer review

- Open access: articles freely available online

- High visibility within the field

Retaining the copyright to your article

Submit your next manuscript at springeropen.com 